\title{
Correction to: European clinical guidelines for Tourette Syndrome and other tic disorders: patients' perspectives on research and treatment
}

Seonaid Morag Anderson ${ }^{1}(\mathbb{D}$ on behalf of on behalf of Tics and Tourette Around the Globe (TTAG) representing Tic and Tourette Syndrome (TS) patient associations around the world ${ }^{1}$

Published online: 13 September 2021

(c) Springer-Verlag GmbH Germany, part of Springer Nature 2021

Correction to: European Child \& Adolescent Psychiatry https://doi.org/10.1007/s00787-021-01854-y

This article is part of the focused issue "Update of the European clinical guidelines for Tourette Syndrome and other tic disorders".

The original article has been corrected. 